\title{
Effects of reinforcement on retention and transfer
}

\author{
ELVIS C. JONES, ED M. EDMONOS AND MARVIN R. MUELLER
}

TEXAS CHRISTIAN UNIVERSITY

Three groups of $S$ s overlearned a list of nonsense syllables under three reinforcement conditions: consistent (CR), partial $(\mathrm{PR})$, and nonreinforcement (NR). After seven days Ss were tested for recall and relearning. They then learned a new list of nonsense syllables. On all tasks, groups that received monetary rewards were superior to the NR group, suggesting that extrinsic reinforcement increases resistance to forgetting. On the transfer task, the PR group performed significantly better than did either the CR or the NR groups, and the $C R$ group was superior to the NR group.

The distinction between learning and performance during acquisition has its counterpart in extinction. The fact that forgetting and failure to respond are often confounded can, no doubt, explain the contradictory findings obtained in some studies (e.g., Hake \& Grant, 1951; Hake, Grant, \& Hornseth, 1951) dealing with the effects of reinforcement on resistance to extinction. Ss may have sufficient incentive to continue to respond, but fail to remember the correct response. On the other hand, Ss may remember the correct response, but fail to respond because there is no extrinsic incentive. Some tasks (e.g., lever pulling) make motivation the critical factor in resistance to extinction, while other tasks (e.g., serial learning) emphasize retention.

Although reinforcement (especially partial reinforcement) is known to generally increase resistance to extinction (Skinner, 1938; Jenkins \& Stanley, 1950), investigators have almost invariably used nonreinforcement of responding as the extinguishing operation and failure to respond at a set rate or magnitude as the criterion of extinction. Most studies also involve simple, easy to remember responses. Thus, it is still unclear whether reinforcement affects retention as well as persistence of responding.

In the present study, three measures of retention (recall, relearning, and transfer) were used to determine if different reinforcement conditions affect retention in addition to persistence of responding. In verbal recall, regardless of Ss' level of motivation, they can perform only if they remember the correct response. On the other hand, motivational variables may affect relearning and transfer. If reinforcement primarily affects motivation, then differentially reinforced groups should differ on relearning and transfer, but not on recall.

In the present experiment, a monetary reward was super-imposed upon a task which no doubt already involved reinforcement. However, the same situation exists with push-buttons (Lewis, 1952), and mazes (Tolman \& Honzik, 1930), where extrinsic and in- trinsic reinforcement differentially affect performance. Moreover, extrinsic reinforcement has been found to be effective in verbal learning experiments (e.g., Grant, Hake, \& Hornseth, 1951),

Method

The Ss were 18 students enrolled in an introductory psychology course. They were randomly assigned to the following three groups: partial reinforcement (PR), consistent reinforcement (CR), and nonreinforcement (NR). Each S learned a list of 10 nonsense syllables. The syllables were randomly selected from the $100 \%$ association value list in Glaze (1928) and were presented on a Gerbrands memory drum in the following order: LON, COL, SUT, VES, DAR, PED, MAK, GUL, NAR, FEL. The exposure time was 3 sec. with a 9 sec. intertrial interval. All Ss were trained to a criterion of 10 errorless trials (not necessarily consecutive). The CR group received five cents for each errorless trial. The PR group received five cents for only $50 \%$ of the trials (randomly determined), and the NR group was never rewarded.

Prior to the experiment Ss were not told that they would be rewarded. On the first correct trial the memory drum was stopped. The Ss in the CR and PR groups were then given the following information: "This is your reward for that trial. The money will notbe taken from you at the end of the experiment." The Ss in the NR group were told: "In a moment the machine will be restarted and you are to continue." On subsequent trials the money was placed into a small dish beside the memory drum without comment. The Ss were not told that they would be tested later.

On the seventh day following learning, Ss relearned the same list to a criterion of one errorless trial. Immediately after relearning the list, they learned a new list which was derived in the same manner as the first list. The syllables were: DEP, FAM, GIV, SEL, LOS, NOV, VIN, MON, PIL, CUS. Although Ss received no reward for learning the second list, the reward dish was present during all trials.

\section{Results and Discussion}

The number of trials and the number of errors to criterion during learning were used as covariates to residualize the scores on all tasks (McNemar, 1962, p. 162). The recall and relearning measures were the number of correct syllables on the first trial of the test session and the number of correct syllables on subsequent trials, respectively. The transfer measure was the number of correct syllables prior to the first errorless trial on the second list of syllables. Because of gross heterogeneity of variance, nonparametric tests were used to analyze the data. 
In recall, the reinforced groups (CR and PR combined) performed significantly better than the NR group $(U=17$, $\mathrm{p}<.05)$. The difference between the PR and CR groups was nonsignificant.

In relearning, the reinforced groups were superior to the NR group $(U=16, p<.05)$. Again, there was no significant difference between the $\mathrm{CR}$ and PR groups.

The analysis of the data in the transfer task was based on a Kruskal-Wallis H-test. Comparisons of all groups resulted in an $\mathrm{H}$-value of 9.58 which is significant beyond the .01 level. Individual group comparisons by U-tests indicated that the $P R$ group was superior to the CR group and that the CR group performed significantly better than did the NR group $(p<$ .05 for all comparisons).

The results indicate (a) that reinforcement increases resistance to forgetting, although partial reinforcement is no more effective than continuous reinforcement, and (b) that reinforcement enhances positive transfer to a new list, with partial reinforcement producing the greatest amount of transfer. While the results do not readily lend support to any specific theory, it is interesting to note that the $\mathbf{P R}$ group performed significantly better than the CR group only in the task (transfer) which is probably most sensitive to motivational variables. This is consonant with motivational explanations of the partial reinforcement effect. On the other hand, competing response theories (e.g., Weinstock, 1954) are supported by the incidental observation that during learning the reinforced groups made more errors after the first correct trial than did the NR group $(U=16, p<.05)$, but made fewer errors during testing.

\section{References}

Glaze, J. A. The association value of nonsense syllables. $J$. genet. Psychol., 1928, 35, 255-267.

Grant, D. A., Hake, H. W., \& Homseth, J. P. Acquisition and extinction of a verbal conditioned response with differing percentages of reinforcement. $J$. exp. Psychol., 1951, 42, 1-5.

Hake, H .W., \& Grant, D. A. Resistance to extinction and the pattern of reinforcement: II. Effect of successive alternation of blocks of reinforced and unreinforced trials upon the conditioned eyelid response to light. $J$. exp. Psychol., 1951, 41, 216-220.

Hake, H. W., Grant, D. A., \& Hornseth, J. P. Resistance to extinction and the pattern of reinforcement: III. The effect of trial patterning in verbal conditioning. J. exp. Psychol., 1951, 41, 221225.

Jenkins, W. o., \& Stanley, J. C., Jr. Partial reinforcement: A review and critique. Psychol. Bull., 1950, 47, 193-234.

Lewis, D. J. Partial reinforcement in a gambling situation. J. exp. Psychol., 1952, 43, 447-450.

McNemar, Q. Psychological statistics. (3rd. ed.), New York: John Wiley, 1962.

Skinner, B. F. The behavior of organisms. New York: AppletonCentury-Crofts, 1938.

Tolman, E. C., \& Honzik, C. H. Introduction and removal of reward and maze performance in rats. Univ. Calif. Publ. Psychol., 1930, 4, 257-275.

Weinstock, s. Resistance to extinction of a running response following partial reinforcement under widely spaced trials. $J$. comp. physiol. Psychol., 1954, 47, 318-322. 